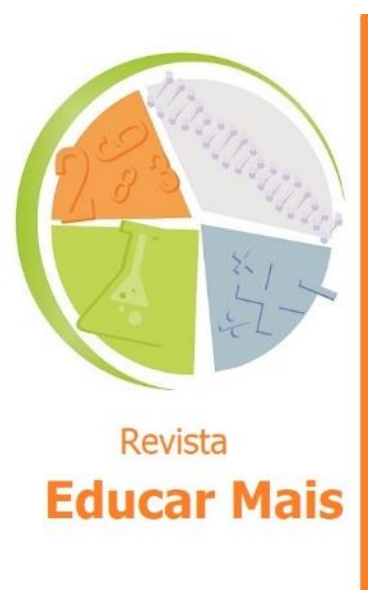

\title{
Qualidade de vida no trabalho remoto compulsório em tempos de pandemia COVID 19: análise em uma instituição federal de educação no sul do Brasil
}

\author{
Quality of life in compulsory remote work in times of a pandemic \\ COVID 19: analysis in a federal education institution in southern Brazil
}

Calidad de vida en el trabajo remoto obligatorio en tiempos de pandemia COVID 19: análisis en una institución federal de educación en el sul del Brasil

\author{
Denise Corrêa Martins Venâncio ${ }^{1}$; ; Stela Mara de Oliveira Rodrigues ${ }^{2}$; \\ Milena Garcia da Silva ${ }^{3}$
}

\section{RESUMO}

Esta pesquisa teve como objetivo identificar, em um censo institucional, perguntas relacionadas à qualidade de vida no trabalho remoto compulsório/QVTRC. Trata-se de uma pesquisa exploratória, descritiva e documental, de natureza qualitativa. O documento, objeto do estudo dessa investigação, foi uma pesquisa realizada pela instituição para conhecer a realidade dos seus trabalhadores nesse novo modelo de trabalho no contexto da pandemia (censo institucional). Constatou-se que havia questões que investigavam a QVTRC, porém o instrumento carecia de outras perguntas que propiciassem a investigação deste fenômeno de forma integral. Diante disso, ao final do trabalho, sugeriu-se inclusão de questionamentos que propiciassem a investigação de todos os fatores pertencentes a cada dimensão constituinte do fenômeno "qualidade de vida no trabalho". Dessa forma, a instituição poderia ter subsídios, advindos de pesquisa quantitativa, para elaboração de intervenções institucionais referentes à QVTRC.

Palavras-chave: QVT; Teletrabalho; COVID.

\begin{abstract}
This research aimed to identify, in an institutional census, questions related to the worker's quality of life in compulsory remote work/QVTRC. It is an exploratory, descriptive and documentary research of a qualitative nature. The document, object of the study of this investigation, was a survey carried out by the institution to understand the reality of its workers in this new work model in the context of the pandemic (institutional census). It was found that there were questions that did investigate the HRQOL, but the instrument lacked other questions that would allow the investigation of this phenomenon in an integral way. Therefore, at the end of this research, it was suggested to include questions that would allow the investigation of all factors belonging to each dimension that constitutes the phenomenon "quality of life at work". Thus, the institution could have
\end{abstract}

\footnotetext{
${ }^{1}$ Bacharel em Administração de Empresas, Técnica em Enfermagem, Licenciada com Complementação Pedagógica em Educação Profissional e Tecnológica, Especialista em Gestão Pública para Educação Profissional e Tecnológica e Especialista em Tecnologia para Educação Profissional. Instituto Federal de Educação, Ciência e Tecnologia de Santa Catarina (IFSC), Florianópolis/SC - Brasil. E-mail: denisevenancio01@hotmail.com

${ }^{2}$ Bacharel em Administração de Empresas e Especialista em Gestão Pública na Educação Profissional Tecnológica. Instituto Federal de Educação, Ciência e Tecnologia de Santa Catarina (IFSC), Florianópolis/SC - Brasil. E-mail: rodriguesstela62@gmail.com

3 Psicóloga, Especialista em Avaliação Psicológica, Gestão de Pessoas por Competências e em Terapia CognitivoComportamental e Mestra em Saúde Mental e Atenção Psicossocial. Instituto Federal de Educação, Ciência e Tecnologia de Santa Catarina (IFSC), Florianópolis/SC - Brasil. E-mail: milena.garcia@ifsc.edu.br
} 
subsidies, arising from quantitative research, for the elaboration of institutional interventions related to the QVTRC.

Keywords: QLW; Telework; COVID.

\section{RESUMEN}

Esta pesquisa tuvo como objetivo identificar, en un censo institucional, preguntas relacionadas a la Calidad de Vida en Trabajo Remoto Obligatorio - CVTRO. Se constituye en una investigación exploratoria, descriptiva y documental, de tipo cualitativo. El documento, objeto de estudio de esta investigación, se refiere a una encuesta realizada por la institución para conocer la realidad de sus trabajadores en este nuevo modelo de trabajo en el contexto de la pandemia (censo institucional). Se encontró que existían problemáticas que investigaban la CVTRO, pero el instrumento necesitaba de otras preguntas que permitiesen la investigación de este fenómeno de forma integral. Por eso, al final del trabajo, fue sugerida la inclusión de cuestionamientos que permitiesen la investigación de todos los factores pertenecientes a cada dimensión que constituye el fenómeno "calidad de vida en el trabajo". De esta forma, la institución podría tener subsidios, provenientes de pesquisa cuantitativa, para la elaboración de intervenciones institucionales referentes a la CVTRO.

Palabras clave: CVT; Teletrabajo; COVID.

\section{INTRODUÇÃO}

No final do ano de 2019, o governo chinês alertou o mundo sobre o surgimento de um novo coronavírus. Devido sua rápida propagação/contaminação pelo mundo, causando milhares de morte, em 11 de março de 2020, a Organização Mundial de Saúde declarou pandemia do novo Coronavírus, chamada de Sars-Cov-2 (Covid-19). No Brasil, a substituição das aulas presenciais por aulas em meios digitais iniciou após a publicação da Portaria no 343, de 17 de março de 2020, do Ministério da Educação (BRASIL, 2020).

No estado de Santa Catarina, a declaração de emergência também ocorreu no dia 17 de março de 2020. O governo estadual declarou emergência em todo território com a assinatura do Decreto 515 (SANTA CATARINA, 2020). Por conta disso, grande parte das organizações e instituições no estado, incluindo as escolas, passaram a flexibilizar o horário de trabalho, o lugar de trabalho e modo de realizar as atividades de trabalho, configurando a aplicação do trabalho remoto ou home office.

Dessa forma, o trabalho precisou ser modificado para ser realizado em casa, sem um planejamento prévio ou com recursos ideais para a sua eficácia. O exercício remoto da profissão, com a atual situação da pandemia, necessitou de gerenciamento de fatores estruturais e psicológicos (MORAES, 2020).

Perante esse contexto e (1) da importância da qualidade de vida no trabalho/QVT como fator promotor de saúde no ambiente de trabalho, (2) da necessidade das instituições conhecerem a percepção dos seus trabalhadores sobre a nova modalidade de trabalho advinda da pandemia de 2020 e (3) das instituições ofertarem ações que minimizem as dificuldades do dia-a-dia de trabalho e potencializem a percepção de QVT, é que essa pesquisa surgiu.

O local de investigação desta pesquisa foi uma instituição federal de educação, localizada no sul do Brasil. Autarquia federal brasileira, vinculado ao Ministério da Educação (MEC). Instituição caracterizada por ofertar ensino público gratuito, nas áreas de educação profissional, científica e tecnológica (IFSC, 2020a). Desde a publicação da Portaria n³43 do MEC e de portaria institucional, 
o órgão encontra-se em atividades não-presenciais (ANP), com seus alunos tendo aulas em meios digitais e seus servidores em teletrabalho/home office (BRASIL, 2020; IFSC, 2020b).

Diante desse cenário, a pergunta que norteou esse estudo foi: quais as ações utilizadas pela instituição para compreender a percepção dos seus servidores sobre a Qualidade de Vida no Trabalho Remoto Compulsório (QVTRC)?

Para responder esse problema de pesquisa, a investigação teve como objetivo geral o de analisar documento institucional elaborado para avaliar as necessidades dos servidores em teletrabalho (Censo Servidores na Covid-19) como instrumento de avaliação da percepção dos servidores sobre a Qualidade de Vida no Trabalho Remoto Compulsório - QVTRC.

\section{FUNDAMENTAÇÃO TEÓRICA}

Para que se entenda a qualidade de vida no trabalho é importante compreender antes o conceito de trabalho. Segundo Dejours (2004), o trabalho é compreendido como tudo aquilo que implica, do ponto de vista humano, o fato de trabalhar: gestos, saber-fazer, um engajamento do corpo, a mobilização da inteligência, a capacidade de refletir, de interpretar e de reagir às situações; é o poder de sentir, de pensar e de inventar, etc. (DEJOURS, 2004).

Entende-se que trabalho não é em primeira instância a relação salarial ou o emprego, mas sim, um certo modo de engajamento da personalidade para responder a uma tarefa delimitada por pressões (materiais e sociais) e que no domínio individual é central para a formação da identidade e para a saúde mental (DEJOURS, 2004).

O teletrabalho pode ser definido, segundo a Organização Internacional do Trabalho- OIT (1998), como uma atividade laboral realizada à distância (trabalho remoto), inclusive em casa (home office), utilizando computadores e dispositivos de comunicação móveis, como telefones, celulares e aplicativos.

Melo Filho (2018) diz que o teletrabalho (home office) exige que os gestores criem métodos de supervisão diferentes dos utilizados tradicionalmente. Um novo estilo de administração que dê atenção às questões ligadas ao desempenho, que leve ao aumento de confiança entre gerência e subordinados e que vise minimizar os possíveis pontos negativos.

Algumas publicações têm ressaltado a importância sobre as boas práticas no trabalho remoto, apresentando o teletrabalho como uma perspectiva positiva do trabalho deslocalizado: destacando a possibilidade de liberdade e autonomia diante do controle externo e com estratégia de estabelecimento do equilíbrio entre vida familiar e trabalho. Mas, também, há nessas publicações, a presença de aspectos negativos do home office: limites de organização do próprio trabalhador, que não estaria preparado para um modelo mais autônomo de trabalho ou sem disposição para exercer o trabalho nestes moldes (OLIVEIRA, 2017).

De acordo com Hara (2011), o trabalho realizado em home office apresenta diversas dificuldades vivenciadas pelo trabalhador entre elas: isolamento profissional e social; redução das oportunidades profissionais; problemas familiares; falta de legislação e vicio ao trabalho. Para organização este molde de executar o trabalho apresenta as seguintes desvantagens: dificuldade em controlar e supervisionar o trabalho; resistência (não aceitação) à mudança por parte dos seus gestores; 
diminuição do foco na empresa por parte do trabalhador (agrega seus serviços paralelo à outras empresas); risco com confiança e confidencialidade.

Segundo Abbad et al. (2020), apesar do alto índice de aprovação, foram encontradas dificuldades muito expressivas nas famílias com crianças pequenas, onde o casal divide os afazeres domésticos e cuidados com os filhos em idade escolar, pois com a pandemia houve à perda de uma rede de apoio familiar e de empregados domésticos, juntamente com o teletrabalho e o home schooling.

Diante desse desafio dos trabalhadores necessitarem se adaptar a uma nova modalidade de trabalho, até então sem planejamento prévio e dividindo a atenção entre o trabalho e as atividades familiares e pessoais - as organizações precisam conhecer quais os aspectos positivos e negativos dessa nova experiência de trabalho. Por isso, compreender qual a percepção dos seus trabalhadores sobre a qualidade de vida no trabalho nessa nova modalidade de atividade laboral é importante.

\subsection{Qualidade de Vida no Trabalho (QVT)}

O tema qualidade de vida no trabalho não é apenas de interesse de pesquisadores, mas desde o princípio da civilização, o homem busca formas de ter uma convivência mais amena em sua luta pela sobrevivência. Desde os tempos mais remotos têm buscado a criação de artefatos, ferramentas e métodos, que possibilitem minimizar os desgastes do trabalho ou torná-lo mais prazeroso (SANT'ANNA; KILIMNIK, 2011).

Estudos revelam que a qualidade de vida no trabalho surgiu na década de 50 em Londres, com os movimentos de lutas de trabalhadores e de estudantes em busca de um trabalho mais justo e com melhores condições. Já na década de 60 , em preocupação com os efeitos do trabalho na saúde e bem-estar do trabalhador, algumas melhorias entraram em vigor, objetivando minimizar os efeitos negativos do trabalho na saúde e bem-estar geral dos trabalhadores (MACEDO; MATOS, 2008).

Essa questão pode ser evidenciada no estudo de Kurogi (2008) quando esclarece que na década de 80, devido ao desenvolvimento do mercado internacional, houve um considerável aumento da concorrência. Neste contexto, ressurgiram com maior ênfase, estudos e pesquisas sobre QVT. Na década de 90, a QVT foi difundida para diversos países.

No Brasil, segundo Ferreira (2011), a QVT tem duas abordagens distintas. A assistencialista/hegemônica e a preventiva/contra hegemônica. A primeira é caracterizada pela responsabilização do trabalhador por sua QVT, que em decorrência da competitividade tem foco na produtividade levada ao extremo e onde o trabalhador é a variável de ajuste, ele é quem tem que ser flexível e o poder de decisão de quem trabalha cotidianamente permanece restrito, vigiado e, na maior parte dos casos, proibido. A segunda abordagem vem como alternativa no sentido de identificar e solucionar os problemas geradores do mal-estar no trabalho, relacionando-se com três dimensões interdependentes (condições, organização e relações de trabalho) e de promover o resgate do sentido humano do trabalho, vendo a eficiência e a eficácia organizacional como resultantes da percepção de bem-estar. É vista como uma tarefa de todos na organização, o que faz com que a produtividade seja uma consequência e não o foco (FERREIRA, 2011).

Para Ferreira (2011), tais dimensões são importantes para avaliar a QVT. De acordo com o autor elas são constituídas por fatores específicos. São eles: 
Quadro 1 - Dimensões da QVT

\begin{tabular}{|c|c|}
\hline Dimensão & Elementos \\
\hline $\begin{array}{l}\text { Condições de Trabalho e Suporte } \\
\text { Organizacional }\end{array}$ & $\begin{array}{l}\text { - Equipamentos arquitetônicos } \\
\text { - } \text { Ambiente físico } \\
\text { - Instrumental; } \\
\text { - } \text { Matéria-prima e } \\
\text { - Suporte organizacional. }\end{array}$ \\
\hline Organização do Trabalho & $\begin{array}{l}\text { - } \quad \text { Divisão do trabalho; } \\
\text { - } \text { Missão, objetivos e metas organizacionais; } \\
\text { - Trabalho prescrito; } \\
\text { - Tempo de trabalho; } \\
\text { - Processo de trabalho; } \\
\text { - Gestão do trabalho e } \\
\text { - } \quad \text { Padrão de conduta. }\end{array}$ \\
\hline Relações Socioprofissionais de Trabalho & $\begin{array}{l}\text { - Relações hierárquicas; } \\
\text { - Relações com os pares e } \\
\text { - } \quad \text { Relações externas. }\end{array}$ \\
\hline Reconhecimento e Crescimento Profissional & $\begin{array}{ll}\text { - } & \text { Reconhecimento e } \\
\text { - } & \text { Crescimento profissional. }\end{array}$ \\
\hline Elo Trabalho-Vida Social & $\begin{array}{l}\text { - Sentido do trabalho; } \\
\text { - Importância da instituição empregadora e } \\
\text { - Vida social. }\end{array}$ \\
\hline
\end{tabular}

Fonte: Adaptado de Ferreira (2011), p. 185 e 186.

\section{PROCEDIMENTOS METODOLÓGICOS}

Para iniciar a pesquisa foi necessário delimitar os seus procedimentos metodológicos. Compreendese que a metodologia é o modo utilizado para realizar a busca das informações necessárias para o entendimento a respeito de um determinado assunto.

"Metodologia é uma disciplina que consiste em estudar, compreender e avaliar os vários métodos disponíveis para a realização de uma pesquisa acadêmica. [...] é a aplicação de procedimentos e técnicas que devem ser observados para construção do conhecimento" (PRODANOV; FREITAS, 2013, p. 14).

Para caracterizar esse estudo foram utilizados os seguintes procedimentos metodológicos:

\section{1 Quanto à abordagem}

A pesquisa foi classificada como qualitativa. A abordagem qualitativa não busca apenas medir um tema, mas descrevê-lo, usando impressões, opiniões e pontos de vista. A pesquisa qualitativa busca se aprofundar em um tema para obter informações sobre as motivações, as ideias e as atitudes das pessoas (MINAYO; DESLANDES, GOMES, 2012).

\section{2 Quanto aos objetivos}

Classifica-se como pesquisa exploratória. Segundo Gil (2008), objetiva familiaridade com o problema objeto da pesquisa, o aprimoramento de ideias ou a descoberta de intuições. Seu planejamento é, 
portanto, bastante flexível, de modo que possibilite a consideração dos mais variados aspectos relativos ao fato estudado.

\section{3 Quanto as técnicas}

A pesquisa classifica-se como uma pesquisa documental, que de acordo com Gil (2008), é muito semelhante à pesquisa bibliográfica, tendo como principal diferença a natureza das fontes, pois a pesquisa bibliográfica se utiliza basicamente das contribuições dos diversos autores sobre determinado assunto, e a documental de materiais que ainda não tiveram tratamento analítico, ou que ainda podem ser refeitos de acordo com os objetos da pesquisa. Os documentos são analisados de "primeira mão", mas existem também aqueles que já foram analisados, mas podem ter outras interpretações.

\subsection{Local da investigação}

A pesquisa foi realizada em uma Instituição Federal de Educação no Sul Do Brasil. A instituição possui 22 campi e cerca de 20 polos de apoio presencial aos cursos EaD, e conta com um quadro de servidores efetivos e temporários, num total de 1.623 docentes e 1.153 técnicos administrativos em educação (PLATAFORMA NILO PEÇANHA, 2020).

\subsection{Coleta de Dados}

Lengert (2020) afirma que a coleta de dados é uma das partes mais importantes na fase de elaboração do trabalho científico. Nesta etapa que a pesquisa será alimentada com informações que irão ajudar a responder a problemática de pesquisa levantada.

A coleta de dados foi realizada através de coleta e análise de informações contidas em documentos institucionais. Nesse caso, um censo (Censo Servidores na Covid 19) aplicado para averiguar situação de servidores no período de trabalho remoto devido à emergência sanitária.

Todos os dados coletados foram analisados qualitativamente e correlacionados para responder aos objetivos propostos para este estudo.

\subsection{Análises dos Dados}

A análise foi realizada através de 3 etapas - pré-análise, exploração do material e tratamento dos dados.

Segundo Gil (2008), a primeira etapa da análise de dados refere-se a pré-análise, onde o autor da pesquisa irá realizar à escolha dos documentos a serem analisados, assim formular uma hipótese. Posteriormente ocorre a segunda etapa que consiste na exploração do material, onde envolve a escolha das unidades, enumeração e sua classificação. A terceira etapa é o tratamento de dados, que constitui em analisar as informações pesquisadas, sem a inferência do autor, buscando então interpretação dos dados para responder a solução do problema.

Esta pesquisa analisou as 42 perguntas do questionário da primeira fase do censo institucional, aplicado aos servidores (Docentes e TAEs), com os estudos da área sobre a constituição do fenômeno QVT. 
Buscou averiguar se as questões elaboradas no instrumento poderiam ser analisadas por uma outra perspectiva, a da QVTRC.

\section{ANÁLISES DOS RESULTADOS}

O objeto de estudo dessa investigação foi o formulário que derivou em uma pesquisa aplicada pela instituição a todos os seus servidores com o intuito de conhecer a realidade de trabalho remoto destes no contexto de pandemia. A instituição aplicou esta pesquisa, no período de 24 de julho a 28 de agosto de 2020. O objetivo foi o de "conhecer em detalhes as necessidades de inclusão digital, saúde mental, alimentação e arranjo familiar, entre outros aspectos relacionados ao bem-estar e ao processo de ensino-aprendizagem da comunidade acadêmica em teletrabalho por conta da pandemia de coronavírus" (Censo Servidores na Covid 19, 2020). O instrumento investigado foi denominado como Censo Servidores na Covid 19, constituído de 42 perguntas e distribuído em 08 blocos, conforme tabela abaixo.

Tabela 1: No de perguntas e blocos de investigação

\begin{tabular}{lc}
\hline \multicolumn{1}{c}{ Blocos Investigados } & $\begin{array}{c}\text { No de } \\
\text { Perguntas }\end{array}$ \\
\hline Termo de Consentimento & 01 \\
Identificação & 03 \\
Grupo de risco & 05 \\
Acesso às informações & 02 \\
Aspectos socioeconômicos e de distanciamento social & 04 \\
Saúde & 09 \\
Atividades não-presenciais & 15 \\
Retorno das atividades presenciais & 03 \\
\hline Total & 42
\end{tabular}

Fonte: Elaborado pelas autoras com dados extraídos do Censo Servidores na Covid 19 (2020)

A partir da exploração do material, constatou-se que das 42 perguntas realizadas nesse instrumento, 15 poderiam ser analisadas a partir de uma outra perspectiva, a de conhecer a percepção dos trabalhadores sobre a qualidade de vida no trabalho remoto compulsório.

Essa pesquisa considerou o fenômeno qualidade de vida no trabalho como sendo uma atuação com base em viés preventivo e de promoção da saúde, que vem como alternativa no sentido de identificar e solucionar os problemas geradores do mal-estar no trabalho (FERREIRA, 2011).

Ferreira (2011) relata que as representações de bem-estar e de mal-estar no trabalho podem ser influenciadas por aspectos relacionados ao trabalho. Ele separa tais aspectos por dimensões, conforme quadro abaixo:

Quadro 2 - Dimensões do Fenômeno da QVT

\begin{tabular}{|l|l|}
\hline \multicolumn{1}{|c|}{ Dimensões } & \multicolumn{1}{c|}{ Itens dos Fatores Estruturantes } \\
\hline $\begin{array}{l}\text { Condições de Trabalho e Suporte } \\
\text { Organizacional }\end{array}$ & $\begin{array}{l}\text { Expressam as condições físicas, materiais, instrumentais } \\
\text { e suporte organizacional. }\end{array}$ \\
\hline Organização do Trabalho & $\begin{array}{l}\text { Expressa as variáveis de tempo, controle, traços das } \\
\text { tarefas e sobrecarga e prescrição. }\end{array}$ \\
\hline
\end{tabular}




\begin{tabular}{|l|l|}
\hline Relações Socioprofissionais de Trabalho & $\begin{array}{l}\text { Expressam as interações sócio-profissionais em termos } \\
\text { de relações com os pares, com as chefias, com os } \\
\text { cidadãos usuários dos serviços públicos, comunicação, } \\
\text { ambiente harmonioso e conflitos. }\end{array}$ \\
\hline Reconhecimento e Crescimento Profissional & $\begin{array}{l}\text { Expressam variáveis relativas ao reconhecimento no } \\
\text { trabalho e ao crescimento profissional. }\end{array}$ \\
\hline Elo Trabalho - Vida Social & $\begin{array}{l}\text { Expressa as percepções sobre a instituição, o trabalho e } \\
\text { as analogias com a vida social. }\end{array}$ \\
\hline
\end{tabular}

Fonte: Políticas de QVT (2017)

Foi a partir dessa compreensão sobre a conceituação do fenômeno que a seleção e o tratamento do material ocorreram.

Para melhor elucidação, seguem quadros com perguntas do censo institucional não selecionadas (quadro $n^{\circ} 3$ ) e selecionadas (quadro no 4), para análise sob a perspectiva da qualidade de vida no trabalho remoto compulsório.

Quadro 3 - Perguntas não selecionadas para compreensão do fenômeno Qualidade de Vida no Trabalho Remoto Compulsório

\begin{tabular}{|c|c|}
\hline Blocos Investigados & Perguntas \\
\hline Termo de Consentimento & Se consente o uso dos dados coletados \\
\hline Grupo de risco & $\begin{array}{l}\text { Se está enquadra em alguma das características apresentadas } \\
\text { Se apresenta alguma das doenças mencionadas } \\
\text { Possui alguma doença crônica não mencionada na questão } 5 \\
\text { Se reside com alguém do grupo de risco } \\
\text { Se está responsável por alguém que necessite de cuidados específicos }\end{array}$ \\
\hline Acesso às informações & $\begin{array}{l}\text { Em que área tem dúvidas com relação a COVID-19 } \\
\text { Se tem acesso regular a máscara de proteção e que tipo }\end{array}$ \\
\hline $\begin{array}{l}\text { Aspectos socioeconômicos e de } \\
\text { distanciamento social }\end{array}$ & $\begin{array}{l}\text { Assinalar as dificuldades enfrentadas no cotidiano social } \\
\text { Como está o seu distanciamento social } \\
\text { Como você tem se sentido } \\
\text { Se a renda familiar foi afetada por conta da pandemia }\end{array}$ \\
\hline Saúde & $\begin{array}{l}\text { Como classifica a própria saúde de maneira geral } \\
\text { Se tem conseguido se alimentar adequadamente } \\
\text { Se foi NÃO na pergunta anterior, por qual motivo } \\
\text { Como está reagindo neste período com relação ao uso de bebida } \\
\text { alcoólica } \\
\text { Se já tinha problema psicológico ou psiquiátrico antes da pandemia } \\
\text { Se neste momento de distanciamento social sentiu necessidade de } \\
\text { atendimento psicológico, psiquiátrico ou terapêutico } \\
\text { Questionário de Identificação de Transtornos Mentais Comuns } \\
\text { (Selfreport } \\
\text { Questionnaire - SRQ-20) - Contendo } 20 \text { questões relacionadas a certas } \\
\text { dores e problemas que podem ter incomodado nos últimos } 30 \text { dias. } \\
\text { Se fez vacina contra gripe este ano } \\
\text { Se fez testagem da Covid-19 e qual o resultado }\end{array}$ \\
\hline Atividades não-presenciais & $\begin{array}{l}\text { Se selecionou "outro" descreva esse ambiente } \\
\text { As próximas } 4 \text { perguntas são somente para os Docentes } \\
\text { Quais as estratégias você mais utiliza no desenvolvimento de ANP } \\
\text { Se não desenvolveu ANP com os alunos, apontar os motivos } \\
\text { O que você espera que aconteça caso as ANP continuem enquanto } \\
\text { estratégia de ensino-aprendizagem? }\end{array}$ \\
\hline
\end{tabular}


Retorno das atividades presenciais
Em sua opinião, qual estrutura fora da instituição é a mais indispensável para o retorno das atividades presenciais?

No possível retorno gradual das atividades presenciais com alunos, na sua opinião, quais estruturas na instituição são imprescindíveis?

Fonte: Elaborado pelas autoras com dados extraídos do Censo Servidores na Covid 19 (2020)

Quadro 4 - Perguntas selecionadas para a compreensão do fenômeno Qualidade de Vida no Trabalho Remoto Compulsório

\begin{tabular}{|l|l|}
\hline Blocos Investigados & $\begin{array}{l}\text { Perguntas que Poderiam ser Analisadas sob outra Perspectiva (QVT } \\
\text { Remoto e Compulsório) }\end{array}$ \\
\hline Identificação & $\begin{array}{l}\text { Campus que pertence } \\
\text { Setor que trabalha } \\
\text { Você é (Docente, TAE ou Estagiário) }\end{array}$ \\
\hline & $\begin{array}{l}\text { Como é o seu ambiente de trabalho em casa? } \\
\text { Tem acesso à internet fora da instituição: } \\
\text { Você está conseguindo realizar suas atividades laborais de forma remota } \\
\text { Quais motivos restringe a atividade remota } \\
\text { Plataformas de reuniões que já utilizou com sucesso } \\
\text { Gostaria de receber capacitação sobre alguma das plataformas reuniões? } \\
\text { Atividades não- } \\
\text { presenciais }\end{array}$ \\
$\begin{array}{l}\text { Que equipamento você usa para realizar as atividades remotamente? } \\
\text { Se tem acesso aos materiais necessários p/ continuidade se suas atividades. } \\
\text { Se necessita de recursos de acessibilidade para desenvolver suas atividades } \\
\text { de trabalho remotamente? } \\
\text { Se gostaria de ter acesso a sala de trabalho na instituição } \\
\text { As próximas 4 perguntas são para os DOCENTES } \\
\text { Em relação ao desenvolvimento de ANP, onde você tem mais dificuldades e } \\
\text { entende que precisaria de capacitação }\end{array}$ \\
\hline $\begin{array}{l}\text { Quando for permitido o retorno às atividades presenciais, considerando a sua } \\
\text { rotina familiar (e possíveis mudanças), bem como a carga horária semanal de } \\
\text { seu vínculo com a instituição, assinale os turnos em que teria maior dificuldade } \\
\text { em atuar. }\end{array}$ \\
\hline \multirow{2}{*}{$\begin{array}{l}\text { Retorno das atividades } \\
\text { presenciais }\end{array}$}
\end{tabular}

Fonte: Elaborado pelas autoras com dados extraídos do Censo Servidores na Covid 19(2020)

As perguntas identificadas no instrumento que poderiam ser analisadas a partir de uma investigação sobre a qualidade de vida no trabalho remoto compulsório estão contidas em três, dos oito blocos de investigação da pesquisa original - "Identificação"; "Atividades não-presenciais" e "Retorno das atividades presenciais".

As três perguntas referentes ao bloco "Identificação" foram mantidas, pois servem para identificar dados sociodemográficos dos participantes (campus, setor e categoria profissional da população pesquisada). Das quinze perguntas do bloco "Atividades não-presenciais - ANP", onze foram selecionadas para essa nova perspectiva de investigação. $\mathrm{E}$, por último, foi avaliada como pertinente nessa nova análise, uma das três questões contidas no bloco "Retorno das Atividades Presenciais".

A seguir, tais questões foram compreendidas e classificadas a partir das dimensões constituintes do fenômeno da QVT. 
Quadro 5 - Perguntas selecionadas no Censo Servidores COVID-19 e distribuídas a partir das dimensões constituintes do fenômeno Qualidade de Vida no Trabalho

\begin{tabular}{|l|l|}
\hline \multicolumn{1}{|c|}{ Dimensões } & \multicolumn{1}{|c|}{ Perguntas } \\
\hline $\begin{array}{l}\text { Condições de Trabalho e Suporte } \\
\text { Organizacional }\end{array}$ & $\begin{array}{l}\text { Como é o seu ambiente de trabalho em casa? } \\
\text { Tem acesso à internet fora da instituição: } \\
\text { Que equipamento você usa para realizar as atividades } \\
\text { remotamente? } \\
\text { Se tem acesso aos materiais necessários p/ continuidade se suas } \\
\text { atividades. } \\
\text { Se necessita de recursos de acessibilidade para desenvolver suas } \\
\text { atividades de trabalho remotamente? } \\
\text { Se gostaria de ter acesso a sala de trabalho na instituição }\end{array}$ \\
\hline Organização do Trabalho & $\begin{array}{l}\text { Você está conseguindo realizar suas atividades laborais de forma } \\
\text { remota } \\
\text { Quais motivos restringe a atividade remota } \\
\text { Plataformas de reuniões que já utilizou com sucesso }\end{array}$ \\
\hline $\begin{array}{l}\text { Relações Socioprofissionais de } \\
\text { Trabalho }\end{array}$ & $\begin{array}{l}\text { Nenhuma } \\
\text { Reconhecimento e Crescimento } \\
\text { Profissional }\end{array}$ \\
\hline $\begin{array}{l}\text { Gostaria de receber capacitação sobre alguma das plataformas } \\
\text { reuniões? } \\
\text { Em relação ao desenvolvimento de ANP, onde você tem mais } \\
\text { dificuldades e entende que precisaria de capacitação. }\end{array}$ \\
\hline $\begin{array}{l}\text { Quando for permitido o retorno às atividades presenciais, } \\
\text { considerando a sua rotina familiar (e possíveis mudanças), bem } \\
\text { como a carga horária semanal de seu vínculo com a instituição, } \\
\text { assinale os turnos em que teria maior dificuldade em atuar. }\end{array}$ \\
\hline
\end{tabular}

Fonte: Elaborado pelas autoras

Somente a dimensão relações socioprofissionais de trabalho, não teve nenhuma pergunta do Censo classificada nessa nova perspectiva. Em contrapartida, a dimensão condições de trabalho e suporte organizacional teve mais de cinco perguntas enquadradas.

Dessa forma, no próximo tópico, apresentam-se sugestões de questões que poderiam complementar a investigação sobre a percepção dos servidores sobre a qualidade de vida no trabalho remoto compulsório.

\section{PROPOSIÇÕES DE MELHORIAS}

As sugestões de melhorias, trabalhadas nesse tópico, foram a formulação de novas perguntas, em número suficiente para que todos os fatores pertencentes a cada dimensão constituinte do fenômeno "qualidade de vida no trabalho" sejam contemplados em uma investigação. A formulação dessas questões considerou o cenário atual no qual os trabalhadores estão vivendo - trabalho remoto sem planejamento prévio devido à emergência sanitária ocasionada pela pandemia COVID-19.

A seguir, encontram-se essas novas sugestões de perguntas, classificadas por fator e dimensão pertencente ao fenômeno.

A partir dessa complementação, a instituição poderia aplicar pesquisa virtual a todos os servidores para conhecer a percepção deles sobre a qualidade de vida no trabalho remoto compulsório. 
Quadro 6 - Complementação de perguntas para conhecer a percepção dos trabalhadores sobre a qualidade de vida no trabalho remoto compulsório

\begin{tabular}{|c|c|}
\hline Dimensões & Perguntas para Pesquisa QVTT \\
\hline $\begin{array}{l}\text { Condições de Trabalho } \\
\text { Suporte rganizacional }\end{array}$ & $\begin{array}{l}\text { Meu posto de trabalho remoto (na minha casa) é adequado para realização } \\
\text { das minhas tarefas. } \\
\text { Tenho os equipamentos necessários (computador, internet, mobiliário } \\
\text { adequado) para realizar minhas atividades de trabalho remotamente. } \\
\text { Tenho as informações necessárias (sistemas, banco de dados) para realizar } \\
\text { minhas atividades de trabalho remotamente. } \\
\text { Recebo suporte técnico da minha chefia imediata para executar meu trabalho } \\
\text { remotamente. } \\
\text { Mesmo trabalhando de forma remota, possuo e tenho acesso aos materiais } \\
\text { (documentos físicos e digitais, livros, softwares, materiais de apoio, etc) } \\
\text { necessários para a continuidade de minhas tarefas. }\end{array}$ \\
\hline $\begin{array}{l}\text { Organização do } \\
\text { Trabalho }\end{array}$ & $\begin{array}{l}\text { Conheço o trabalho que devo realizar remotamente. } \\
\text { No trabalho remoto, consigo expor minhas ideias à chefia imediata com o } \\
\text { intuito de melhorar meus processos de trabalho. } \\
\text { Estou satisfeito com a autonomia que o trabalho remoto me trouxe para } \\
\text { desempenhar minhas tarefas laborais. } \\
\text { A quantidade de atividades que executo remotamente é adequada à minha } \\
\text { carga horária de trabalho. } \\
\text { Eu recebo demandas de trabalho somente no horário que estipulei para } \\
\text { trabalhar. } \\
\text { Consigo finalizar minhas atividades de trabalho, de forma remota, sem } \\
\text { depender do trabalho de outro colega. }\end{array}$ \\
\hline $\begin{array}{l}\text { Relações } \\
\text { Socioprofissionais de } \\
\text { Trabalho }\end{array}$ & $\begin{array}{l}\text { Minha chefia imediata demonstra disposição em me ajudar nesse momento } \\
\text { de trabalho remoto. } \\
\text { Meus colegas de trabalho demonstram disposição em me ajudar nesse } \\
\text { momento de trabalho remoto. } \\
\text { Apesar do distanciamento social, sinto-me próximo da minha equipe de } \\
\text { trabalho. } \\
\text { Na minha equipe, os conflitos diminuíram com o trabalho remoto. } \\
\text { A comunicação na minha equipe de trabalho, nesse momento de atividades } \\
\text { remotas, está ocorrendo de forma satisfatória. }\end{array}$ \\
\hline $\begin{array}{l}\text { Reconhecimento e } \\
\text { Crescimento Profissional }\end{array}$ & $\begin{array}{l}\text { Minha chefia reconhece meu empenho para superar as dificuldades que } \\
\text { surgem no trabalho remoto. } \\
\text { Minha chefia oferece feedbacks sobre as minhas tarefas neste momento de } \\
\text { trabalho remoto. } \\
\text { Meus colegas reconhecem a importância das minhas tarefas neste momento } \\
\text { de trabalho remoto. } \\
\text { Recebo capacitação que me auxiliaram para trabalhar remotamente. }\end{array}$ \\
\hline $\begin{array}{l}\text { Elo Trabalho - Vida } \\
\text { Social }\end{array}$ & $\begin{array}{l}\text { Consigo conciliar o trabalho remoto e a minha vida pessoal. } \\
\text { Sinto que meu trabalho é útil para a sociedade, mesmo sendo realizado de } \\
\text { forma remota. } \\
\text { Eu gosto de trabalhar remotamente. } \\
\text { Sinto orgulho de trabalhar na instituição. } \\
\text { A instituição preocupa-se com minha qualidade de vida em tempos de trabalho } \\
\text { remoto. }\end{array}$ \\
\hline
\end{tabular}

Fonte: Elaborado pelas autoras

Importante destacar que estas perguntas não inviabilizam as demais perguntas realizadas no censo. 


\section{CONSIDERAÇÕES FINAIS}

A Qualidade Vida no Trabalho visa atribuir, por intermédio dos gestores e dirigentes, uma organização mais humanizada, que proporciona um ambiente saudável, com condições físicas e socioambientais aos seus servidores, tendo por resultado um melhor desempenho e produtividade. $O$ elo entre a vida pessoal e a vida profissional e a busca pelo equilíbrio, proporciona ao profissional uma melhor QVT. Esse conjunto de ações possui ligação que não tem como separar a vida profissional da vida pessoal, pois uma influencia diretamente na outra, afetando seu comportamento, rendimento e resultados. Eles não são apenas recursos humanos, mas sim, parceiros que contribuem para o crescimento da organização.

Após a determinação governamental de isolamento social como medida provisória para contenção de propagação do vírus COVID 19, os trabalhadores sem escolha, se viram diante de uma nova modalidade de trabalho, o teletrabalho compulsório, sem nenhum planejamento para tal.

No teletrabalho compulsório, apesar do alto índice de aprovação, foram encontradas dificuldades muito expressivas nas famílias com crianças pequenas, onde o casal divide os afazeres domésticos e cuidados com os filhos em idade escolar.

A instituição tem a Política de QVT que é um instrumento que preconiza a investigação de bem-estar de seus servidores e orienta sobre a estruturação de ações de QVT, para alcançar o bem-estar.

O censo institucional poderia também ter sido utilizado em parte, como instrumento de avaliação da QVT e atender a preconização contida na política institucional de QVT, que é de avaliar este fenômeno de 3 em 3 anos, levando em consideração o novo ambiente e modalidade de trabalho que é o teletrabalho.

\section{REFERÊNCIAS}

ABBAD, G. S. et al. Percepções de teletrabalhadores e trabalhadores presenciais sobre desenho do trabalho. Revista Piscologia: Organização e trabalho. v. 19, n. 4, p. 772-780, 2020. Disponível em: http://pepsic.bvsalud.org/pdf/rpot/v19n4/v19n4a06.pdf. Acesso em: 12 out. 2020.

BRASIL. Ministério da Educação. Portaria no 343, de 17 de março de 2020. Disponível em: https://abmes.org.br/arquivos/legislacoes/Portaria-mec-343-2020-03-17.pdf. Acesso em: 10 set. 2020.

DEJOURS, C. Subjetividade, trabalho e ação. Revista Produção. v. 14, n. 3, p. 027-034, set./dez. 2004. Disponível em: https://www.scielo.br/pdf/prod/v14n3/v14n3a03.pdf. Acesso em: 12 out. 2020.

FERREIRA, M. C. Inventário de Avaliação de Qualidade de Vida no Trabalho (IA_QVT): Instrumento de Diagnóstico e Monitoramento de QVT nas Organizações. 2009. In: REUNIÃO DA SOCIEDADE BRASILEIRA PARA O PROGRESSO DA CIÊNCIA, 61., 2009, Manaus, AM. Anais [...]. Manaus, AM, 2009.

FERREIRA, M. C. Qualidade de Vida no Trabalho: uma abordagem centrada no olhar dos trabalhadores. Brasília, DF: Ler, Pensar, Agir, 2011.

GIL. A. C. Métodos e técnicas de pesquisa social. 6. ed. São Paulo: Atlas. 2008. 
HARA, C. L. Home office e as Tecnologias de Acesso Remoto. São Paulo, 2011. Disponível em: http://www.fatecsp.br/dti/tcc/tcc0004.pdf. Acesso em: 28 nov. 2020.

IFSC. IFSC terá política de qualidade de vida no trabalho. 2017. Disponível em: https://linkdigital.ifsc.edu.br/2017/04/28/ifsc-tera-politica-de-qualidade-de-vida-no-trabalho/. Acesso em: 25 out. 2020.

IFSC. O IFSC. 2020a. Disponível em: https://www.ifsc.edu.br/o-ifsc. Acesso em: 25 out. 2020.

IFSC. Portaria do(a) Reitor(a) $\mathbf{n}^{\circ} \mathbf{1 1 7 8}$, de 16 de março de 2020. 2020b. Disponível em: https://www.ifsc.edu.br/documents/30681/1852909/Portaria+retificada/6ace3bca-9a62-4ff7-a0c292352072ada4?version=1.0. Acesso em: 20 out. 2020.

KUROGI, M. S. Qualidade de vida no trabalho e suas diversas abordagens. Revista de ciências gerenciais, Anápolis, v. 12, n. 16, p. 49-62, 2008. Disponível em:

https://revista.pgsskroton.com/index.php/rcger/article/view/2642. Acesso em: 28 nov. 2020.

LENGERT, Caroline. Pesquisa em Tecnologias Educacionais. 2020. Disponível em: https://moodle.ead.ifsc.edu.br/mod/book/view.php?id=111115. Acesso em: 25 out. 2020.

LIMONGI-FRANÇA, A. C. Qualidade de Vida no Trabalho - QVT: conceito e práticas nas empresas da sociedade pós-industrial. 2. ed. São Paulo: Atlas, 2004.

MACEDO, J.; MATOS, R. D. Qualidade de Vida no Trabalho: um estudo realizado com os funcionários da UNICENTRO, do Campus de Irati. In: CONGRESSO INTERNACIONAL DE ADMINISTRAÇÃO, 2008. Ponta Grossa, PR. Anais [...]. Ponta Grossa, PR, 2008.

MELO FILHO, J. C. Desafios da gestão de pessoas na área de home office. Revista Científica Multidisciplinar Núcleo do Conhecimento. v. 8, n. 11, p. 70- 81, 2018.

MINAYO, M. C. S.; DESLANDES, S. F.; GOMES, R. Pesquisa social: teoria, método e criatividade. 29. ed. Petrópolis: Vozes, 2012.

MORAES, M. M. (org.). Os impactos da pandemia para o trabalhador e suas relações com o trabalho: SBPOT. Porto Alegre: Artmed, 2021.

OIT. Declaração da OIT sobre os princípios e direitos fundamentais no trabalho e seu seguimento. Gênebra, 1998. Disponível em: https://www.ilo.org/wcmsp5/groups/public/--americas/---ro-lima/---ilo-brasilia/documents/publication/wcms_230648.pdf.Acesso em: 12 out. 2021.

OLIVEIRA, D. R. Do fim do trabalho ao trabalho sem fim: o trabalho e a vida dos trabalhadores digitais em Home office. 2017. Tese (Doutorado em Sociologia) - Universidade Federal de São Carlos, São Carlos, 2017. Disponível em:

https://repositorio.ufscar.br/bitstream/handle/ufscar/10792/TESE_OLIVEIRA_DANIELA\%20RIBEIRO .pdf?sequence=1\&isAllowed=y. Acesso em: 28 nov. 2021.

\section{PLATAFORMA NILO PEÇANHA. Rede Federal de Educação Profissional, Científica e}

Tecnológica 2020. Disponível em: http://plataformanilopecanha.mec.gov.br/2020.html Acesso em: 12 out. 2021.

PRODANOV, C. C.; FREITAS, E. C. Metodologia do Trabalho Científico: métodos e técnicas de pesquisa e do trabalho acadêmico. 2. ed. Novo Hamburgo: FEEVALE, 2013. 
SANT'ANNA, A. S.; KILIMNIK, Z. Qualidade de Vida no Trabalho: fundamentos e Abordagens. Rio de Janeiro: Elsevier, 2011.

SANTA CATARINA. Decreto no 515, de 17 de março de 2020. Declara situação de emergência em todo o território catarinense. Estado de Santa Catarina. Florianópolis, 17 de março de 2020. Disponível em: http://dados.sc.gov.br/dataset/149a36ac-19c6-47b3-b8739c0512f7a4db/resource/73d09d8d-3e06-4347-8442-100d35280230/download/decreto_51517.03.2020.pdf. Acesso em: 27 nov. 2021.

Submissão: 01/12/2021

Aceito: 01/02/2022 